\title{
Features of Emotional Experiences in Individuals with Personality Disorders
}

\begin{abstract}
Personality disorders (PDs) are marked by significant disturbances in the way of experiencing oneself, others and the world around. Yet there is paucity of research on the nature of emotional experiences in these disorders. The aim of this study was to examine whether and how emotional experience of individuals with ten distinct forms of PDs distinguished in DSM differs from those without PDs. The study was conducted via the Internet on a large nonclinical sample $(N=3509)$. Participants were administered a PDs measure and a performance task assessing three features of emotional experiences: emotional sensitivity, the valence of experienced emotions and the profile of five components constituting an emotion. As predicted, PDs sufferers experienced emotions differently from controls. Results demonstrated that individuals with all PDs were more receptive to emotional elicitation and displayed higher negative emotionality and a deficiency in the affective component of experienced emotions.
\end{abstract}

Key words: personality disorders, emotional experience, emotional sensitivity, emotional valence, components of emotions

Since personality disorders (PDs) have been distinguished from other clinical syndromes and placed on a separate diagnostic axis in DSM-III (APA, 1980), interest in personality pathology has expanded significantly. Although the body of literature on PDs is constantly growing and a few promising therapeutic systems for PDs have been developed so far, many phenomena are still left unexplained (Widiger, 2007). That is due to, among others, the concentration on description, classification and assessment of PDs, rather than on an explanation of their nature and the scarcity of empirical research on PDs, with borderline and antisocial PD being the only exceptions (Emmelkamp \& Kamhuis, 2007). Clonninger (2007) also noted that the understanding of PDs is obscured by the fact that clinicians dealing with PDs too often revolve around one theory, usually quite isolated on general psychology grounds. Hence we have tried to broaden the understanding of PDs by examining clinical, as well as empirical, data and employing contemporary knowledge from basic psychology branches.

In particular, we strive to utilize recent findings in psychology of emotions, as emotional disturbances appear to play one of the most important roles in PDs. Considering emotional dysfunction as a key factor in PDs is not only shared by major PDs theories and therapies (Magnavita \& Carlson, 2003), but it is also consistent with clinical observation since all PDs are characterized by symptoms referring to deficient emotional functioning, such as irritability and intensive anger, excessive social anxiety and other fears, emotional coldness, lack of empathy, inappropriate affect, shallow or extreme expression of emotions (Kring, 2009). Admittedly, recent advancements in psychology of emotions have already made an enormous impact on psychopathology field, also in the personality disorders domain. Constructs such as emotional information processing (Bland, Williams, Scharer \& Manning, 2004), emotional granularity (Suvak, Sloan, Zanarini \& Barret, 2011) and affect or emotional dysregulation have been successfully adopted in the understanding of borderline PD, with the latter becoming considered as a core feature of this disorder (Linehan, 1993). The concept of emotional processing has also been employed in studies on schizotypal $\mathrm{PD}$, resulting in the recognition of low emotional clarity and high emotional attention as specific for this disorder (Berenbaum et al., 2006; Kerns, 2005). Nonetheless, much of the recent conceptualizations and findings on emotions

\footnotetext{
* University of Social Sciences and Humanities, Faculty of Psychology in Warsaw, Poland, ewa.trzebinska@swps.edu.pl

** University of Social Sciences and Humanities, Faculty of Psychology in Warsaw, Poland, anna.gabinska@swps.edu.pl
} 
Ewa Trzebińska, Anna Gabińska

still await their application in order to provide a better insight into personality pathology.

We adopted two approaches in the examination of emotional phenomena in PDs: developmental and structural. From a developmental point of view, one of the possible significant factors contributing to PDs emotionality is childhood abuse. According to many theoretical models and a rich body of research data, early emotional exploitation, neglect or violence are considered as key risk factors for the development of personality pathology (Emmelkamp \& Kamphuis, 2007; Johnson et al., 2001). Some researchers note that maltreatment and abandonment in childhood may alter brain structures and functioning by triggering the development of survival-adaptive changes like oversensitivity to interpersonal cues, vigilant threat detection/ expectancies and impulsive reward-seeking as compensatory processes (Teicher, Andersen, Polcari, Anderson, Navalta \& Kim, 2003). They further argue that these changes may form a syndrome of over-readiness to react emotionally that prepares the adult brain to adapt to a dangerous world. Therefore, PDs pathology may be associated with high emotional sensitivity and high emotional negativity.

The structural approach to emotional disturbances in PDs emphasizes the importance of the shape of an emotional experience. Current models postulate that emotions are valenced and self-organizing, complex reactions elicited by meaningful events (Frijda, 2009). Widely accepted componential theories of emotion, and particularly the component process model of emotion (Scherer, 2000), assume that emotions consist of several components, which coexist and regulate each other over time and within a particular context. Although there is no consensus as to the exact enumeration of emotion components, the following five are highlighted and mentioned most often: (1) cognitive phenomena, by means of which the appraisal of eliciting objects and events takes place, which thus account for the understanding of the context of emotional arousal, (2) neurophysiological phenomena, which represent a bodily grounding of emotional reaction, (3) motor and other behavioral phenomena, which are the expression of the character and aim of emotional reaction, (4) motivational phenomena, which set up and direct an action, and (5) affective phenomena, which represent a particular positively or negatively valenced activation arising from the evaluation of stimulus meaning by specialized brain systems ${ }^{1}$. It is assumed that every emotion involves a distinct configuration of these psychological and physiological functions, which become synchronized for a limited period of time. Therefore, differentiation of emotions is based on a specific configuration of changes in these components (Scherer, 2002).

Every component of emotion serves a particular role in adaptation to emotional stimuli. Depending on the function of emotions, each component might be viewed as the most vital constituent of the emotional process. However, the affective aspect is often recognized as the most prominent facet of emotion as it arises from an ongoing monitoring of the internal state and its interaction with the immediate context, appoints specific valence to all other emotional components and determines their energy level (Frijda, 2005). That rule applies above all to the conscious experience of emotions, because affective phenomena felt as pleasure or displeasure integrate and direct all components of emotional episodes, guiding contextadequate action and allowing for regulation and control of feeling as a whole (Scherer, 2000). In addition, the extent to which the feeling of pleasure or displeasure is emphasized in verbal reports of emotional experience represents a level of sensitivity to emotional information (Feldman Barrett \& Niedenthal, 2004). The difficulties arising from PDs mainly evolve around personal identity, emotion regulation and disturbances in interpersonal relationships - the way, in which one typically experiences and responds to oneself, others and the world around. Thus, we assumed that these are the problems of emotional misguidance that reflect a faulty "architecture" of emotional experiences - an inadequate arrangement of consciously accessible emotion components. The affective component, the most salient facet of emotional experiences of healthy individuals, is possibly hindered by other aspects of emotion in those with PDs.

\section{Method}

The current study investigated the features of emotional experience in individuals with PDs. Due to the paucity of research on psychological mechanisms including all forms of PDs distinguished in DSM, we aimed to include every one of them. A study that intends to investigate the differences among ten forms of PDs obviously requires ten independent groups of participants, each fulfilling criteria of only one particular disorder. Although the categorical understanding of PDs as a separate clinical entities was a subject of criticism, it remains still valid in the DSM-5 (APA, 2013). Retaining in DSM-5 after long and in-depth discussion the same 10 forms of PDs, which were described in the DSM-IV-TR (APA, 2000), asserts that the available empirical evidence and clinical observations speak still strongly in favor of the existence of described syndromes and the legitimacy of treating them as a separate forms of pathological personality dysfunction, despite the wellknown difficulties in their diagnosis and comorbidity.

Taking into account that in clinical settings comorbidity among various PDs and their co-occurrence with Axis-I disorders is the rule, rather than the exception, we decided to conduct our study on the general population as the reported levels of PDs comorbidity in communities are relatively lower (Emmelkamp \& Kamhuis, 2007). Although studies in general population typically do not involve a precise and in-depth, clinical assessment of PDs, as it is difficult and time-consuming, they are not, however, limited by small sample sizes as clinical research is

\footnotetext{
${ }^{1}$ Componential theories of emotion make a clear distinction between the notion emotion and affect, viewing the latter as the most basic and elementary
} affective reaction, constituting the basis for emotion. Emotion is thus conceptualized as a complex affective reaction construed around affect. 
(Gardner, Qualter \& Tremblay, 2010). Therefore they allow to detect small, but significant effects, which is crucial for exploratory research, such as ours.

Given the $12-15 \%$ prevalence rate of PDs in communities and the frequent co-occurrence among them (Mattia \& Zimmerman, 2001; Torgensen, 2005), research had to include a few thousands participants if all PDs were to be investigated. Thus our data was collected as part of a larger, Internet-based research program on the emotional premises of PDs. We decided to conduct the study via the Internet due to the extensive access to participants the Internet yields. Farther, as Reips (2002) noted, Internet-based studies offer varied additional benefits such as reduced costs, external validity and a high degree of automation (low maintenance, limited experimenter effects). Nonetheless, an Internet study required the application of specific precautions. We implied client-side processing to reduce errors caused by network traffic and server availability. At the same time, as such measurements also depend on the processing power of participants' computers, Flash technology was implemented. A number of procedures, suggested by Reips (2002), were applied with the aim of reducing the dropout rate: questions about personal information at the beginning of the study, a mention of its scientific character, personalization, information on estimated duration, a list of software requirements, technical pretests, a promise of immediate feedback, rewards and practice trials. In order to increase result reliability two-fold precautions were taken: firstly, multiple submission was controlled by the means of IP address collection; secondly, participants who did not complete the study, finished it in less than 15 minutes or more than 60 minutes were excluded from final analysis.

\section{Participants}

3509 people completed all of the provided measures and fulfilled all the formal requirements outlined above. Sample ranged in age from 18 to 65 years $(M=24,83 S D=$ $8,507)$ and was mostly female $(61 \%)$. The majority resided in cities, either big $(54,5 \%)$ or medium-sized $(22,2 \%)$. The rest lived in smaller towns $(15,1 \%)$ or villages $(8,1 \%)$. $79,9 \%$ of participants were high school graduates, $46,3 \%$ had university level education - either graduate $(27,4 \%)$ or undergraduate $(18,9 \%)$.

The study was addressed to all adult Internet users. It was announced through various mailing lists, topicrelated chat forums, Internet ads, as well as via private websites. Links to the study were placed in various Web locations addressed at different age, interest, educational background and socioeconomic status groups. Participation was voluntary and not financially rewarded. However, those who completed the whole study could obtain feedback based on their responses and take part in a lottery with a Nano iPOD and psychology books as prizes.

\section{Procedure}

Participants accessed the study website and read a description with a set of general instructions, accompanied by an informed consent statement. If they agreed to participate, they were asked to answer several demographic questions and then to complete Lifestyle 05/FS Questionnaire, a PD measure, followed by the performance task assessing features of emotional experiences.

\section{Measures}

Personality disorders were measured using Lifestyle 05/FS Questionnaire, a shortened, electronic version of Lifestyle 05/F Questionnaire (Trzebińska \& Lasota, 2009), a self-report measure that includes ten scales designed to assess the frequency of symptoms characteristic for all ten forms of PDs. The scales contain from 9 (antisocial and avoidant PD scales) to 13 items (paranoid PD scale) covering all DSM-IV-TR PDs diagnostic criteria. The symptoms are represented by one to three items, whose frequency is assessed on a 7-point Likert scale from 0 (never) to 6 (very often). Participants are instructed to consider their entire lifespan, not only the current period of life. For each scale a mean score is calculated, with higher scores indicating greater symptom frequency of a particular PD. The scales show high internal consistency, with Cronbach's $\alpha$ ranging from 0,74 for obsessive-compulsive and schizoid scales to 0,90 for avoidant scale. In this sample $\alpha$ 's ranged from 0,71 for obsessive-compulsive scale to 0,90 for avoidant scale. Lifestyle 05/FS Questionnaire has been used in many previously studies, proving to be useful in distinguishing different forms of PDs (Dacko, 2011; Trzebińska \& Balsam, 2013; Trzebińska \& Gabińska, 2008).

To identify individuals with PDs, we adopted the rule according to which a particular PD diagnostic criterion was fulfilled if the score for item relevant to this criterion was higher than a set cut-off point. A particular PD was identified if a sufficient number of criteria for this PD was fulfilled according to DSM-IV-TR guidelines (i.e. for borderline PD five out of nine and for paranoid PD four out of seven criteria). Since there is growing evidence that in the case of PDs assessment the forms of manifestations of PDs are at least partly dependent on age and gender differences (Balsis, Woods, Gleason \& Oltmanns, 2007; Lynam \& Widiger, 2007; Widiger \& Samuel, 2005) and items' scores distribution obtained in our study stood in line with this assertion, cut-off points were established for each item of each PD, separately for men and women, and three age groups. A cut-off point for each item was set on the value, which delimited $10 \%$ of the highest scores, while never dropping below a 3 rating (signifying sometimes). Such low value was selected to control false positive diagnosis rate as such errors in contrast with false negative diagnosis are more frequent in PD assessment implementing self-report inventories (Kaye \& Shea, 2000; Widiger \& Cooker, 2002).

Proportions of participants in the sample with particular PDs are shown in Table 1. (see page 150) Participants meeting criteria for only one particular PD varied significantly in number. Therefore, groups were equalized: the approximate number of participants per group was set at no more than 20 individuals with the highest symptoms frequency for the corresponding PD. The control 
group was formed by participants not meeting any of PDs criteria. Final numbers of participants in each PD group and the control group are presented in Table 2, which displays mean scores of symptom frequency of distinct PDs in each of the groups. Conducted Tamhane's T2 post-hoc test ( $p$ $<0,05$ ) revealed that groups with participants identified with a particular PD reported significantly higher symptom frequency specific for that PD than any other group. Thus the adopted selection procedure allows to assume that individuals qualified to a particular PD group met clinical criteria of only that corresponding PD and no other.

Emotional experience features were measured by a sorting task, inspired by Linville's (1985) self-complexity measure. Assuming a multicomponential and processual nature of emotions (Frijda, 2005; Scherer, 2000), the assessment required a measurement of different aspects of feelings as directly as possible. Accordingly, we developed a performance task, in which data on participants' subjective feelings was obtained during the actual emotional experiences. The task has a two-fold structure. In the first stage, 16 pictures appear in succession on a computer screen; each picture represents a human figure, which expresses an emotion via distinctive body positions and gestures. The figures are drawn schematically, so that only an outline is visible, lacking any personal, age and sex characteristics. Participants are asked to experience the same feeling the figure does and indicate whether it happened or not by clicking either the "I feel it" or "I don't feel it" button, which both appear under the picture. Next, participants are exposed to the figures, whose emotional states they were able to feel previously. This time each figure appears surrounded by a set of 50 expressions, the same for all the figures and presented in a fixed arrangement. Each expression refers to one of the five components involved in an emotional process - the cognitive phenomena (i.e. everything depends on me), the affective phenomena (i.e. that's what I like), the motivational phenomena (i.e. I need to have it), physiological phenomena (i.e. I breathe deeply) and motor phenomena (i.e. I turn back). Participants are once again asked to feel the emotion depicted by the figure and choose (on the basis of the very first impression) all the expressions that describe this feeling. Responses are made with a mouse, by clicking on a button with an expression written on it. There are 10 expressions representative for each of the 5 aspects of an emotional state in the set, 5 of them with a positive valence and the other 5 with a negative valence. Therefore the set consists of 25 positively and 25 negatively valenced expressions. All the pictures and expressions were selected from our previous studies as they proved to effectively elicit different emotions (Trzebińska, 2002).

Table 1. Distribution of distinct PDs in the sample

\begin{tabular}{lcccc}
\hline & \multicolumn{2}{c}{$\begin{array}{c}\text { Meeting DSM-IV } \\
\text { criteria for at least } \\
\text { one PD }\end{array}$} & \multicolumn{2}{c}{$\begin{array}{c}\text { Meeting DSM-IV } \\
\text { criteria for only one } \\
\text { PD }\end{array}$} \\
\cline { 2 - 5 } PDs & $\%$ & $n$ & $\%$ & $n$ \\
\hline borderline & 4,5 & 155 & 0,5 & 17 \\
dependent & 3,7 & 128 & 0,9 & 32 \\
avoidant & 2,8 & 97 & 0,4 & 14 \\
paranoid & 6,1 & 210 & 1,2 & 40 \\
schizoid & 4,8 & 167 & 1,3 & 46 \\
schizotypal & 8,6 & 299 & 2,1 & 73 \\
obsessive- & 1,9 & 65 & 0,7 & 23 \\
compulsive & 6 & 209 & 2,4 & 82 \\
antisocial & 4,7 & 163 & 1,0 & 36 \\
narcissistic & 6,1 & 211 & 2,3 & 79 \\
histronic & & & &
\end{tabular}

Table 2. Mean symptoms frequency of all PDs in groups with particular PDs and in the control group

\begin{tabular}{|c|c|c|c|c|c|c|c|c|c|c|c|}
\hline \multirow[b]{2}{*}{ Group } & \multirow[b]{2}{*}{$n$} & \multicolumn{10}{|c|}{ PD symptom frequency } \\
\hline & & $\mathrm{BDL}$ & DEP & AVD & PAR & SZD & SZT & OBS & ATS & NAR & HST \\
\hline $\mathrm{BDL}$ & 17 & 4.52 & 3.67 & 3.65 & 2.78 & 3.04 & 3.68 & 2.80 & 1.75 & 2.27 & 2.83 \\
\hline DEP & 20 & 3.68 & 4.97 & 4.07 & 2.94 & 3.09 & 3.83 & 3.02 & 1.56 & 2.85 & 2.81 \\
\hline AVD & 14 & 3.21 & 3.49 & 5.37 & 3.49 & 3.60 & 3.40 & 3.07 & 1.13 & 2.48 & 2.13 \\
\hline PAR & 19 & 3.35 & 3.10 & 2.98 & 4.32 & 3.08 & 3.96 & 3.40 & 1.25 & 2.99 & 2.84 \\
\hline SZD & 22 & 3.07 & 2.24 & 3.62 & 2.73 & 4.69 & 3.54 & 3.14 & 1.73 & 2.69 & 2.60 \\
\hline SZT & 22 & 3.27 & 2.74 & 3.03 & 3.18 & 3.33 & 5.00 & 3.10 & 1.79 & 3.63 & 3.33 \\
\hline OBS & 20 & 1.71 & 1.82 & 2.23 & 1.81 & 2.37 & 2.84 & 4.53 & 0.71 & 2.82 & 2.86 \\
\hline ATS & 20 & 3.12 & 2.03 & 2.03 & 2.80 & 2.76 & 3.58 & 2.19 & 4.07 & 4.22 & 3.59 \\
\hline NAR & 21 & 2.17 & 2.06 & 1.59 & 2.44 & 2.24 & 3.41 & 2.96 & 2.20 & 4.75 & 3.92 \\
\hline HST & 19 & 2.26 & 2.02 & 1.70 & 2.29 & 1.98 & 3.40 & 2.99 & 1.99 & 3.64 & 5.03 \\
\hline NoPD & 20 & 0.61 & 0.80 & 0.67 & 0.65 & 1.31 & 0.99 & 1.94 & 0.37 & 1.06 & 1.55 \\
\hline
\end{tabular}

Note. BDL means borderline, DEP dependent, AVD avoidant, PAR paranoid, SZD schizoid, SZT schizotypal, OBS obsessive-compulsive, ATS antisocial, NAR narcissistic, HTS histronic and NoPD control group. 
Participants' responses given in the first and second stages of the sorting task allow to assess the following characteristics of emotions: emotional sensitivity, the valence of felt emotions and the profile of components of the emotional experience. Emotional sensitivity was assessed by the number of elicited feelings in the first stage of the task. Valence was measured by positivity and negativity indices. The former was the ratio of emotions experienced in the second stage as mainly positive (described with at least $90 \%$ of positive expressions among all chosen) to all experienced emotions; the latter was the ratio of emotions experienced as mainly negative (described with at least $90 \%$ of negative expressions among all chosen) to all experienced emotions. There were five indices of feeling components - affect, motivation, cognitive appraisal, physiology and behavior - assessed as the ratio of expressions corresponding to a particular emotional component to all the expressions chosen to describe all emotions experienced in the second stage.

\section{Results}

\section{Emotional sensitivity}

We predicted that individuals with PDs would be more prone to emotional activation than those without PDs. To test this hypothesis the number of indicated feelings was submitted to ANOVA. Analysis revealed that groups differ in line with our prediction, $F(10,203)=3,11, p=0,001$, $\eta^{2}=0,13$ (Figure 1). All PDs groups except the ATS group obtained a significantly higher number of elicited feelings than the NoPD group. The difference between NoPD and ATS groups reached the level of statistical tendency ( $p=$ 0,079).

Figure 1. Number of felt emotions as a function of PDs.



Note. BDL means borderline, DEP dependent, AVD avoidant, PAR paranoid, SZD schizoid, SZT schizotypal, OBS obsessive-compulsive, ATS antisocial, NAR narcissistic, HTS histronic and NoPD control group.

Figure 2. Positivity and negativity scores as a function of PDs.



Note. BDL means borderline, DEP dependent, AVD avoidant, PAR paranoid, SZD schizoid, SZT schizotypal, OBS obsessive-compulsive, ATS antisocial, NAR narcissistic, HTS histronic and NoPD control group. 


\section{Emotional valence}

To test the prediction that emotional experiences of those with PDs are more negatively valenced than emotional experiences of individuals without PDs, standardized positivity and negativity scores were submitted to a $11 \times$ 2 mixed model ANOVA with PDs as the between-subjects factor and valence of felt emotions as the within-subjects factor. An effect of valence was observed, $F(1,202)=21,17$, $p<0,001 \eta^{2}=0,10$. Participants had more positive $(M=$ $0,28, S D=1,06)$ than negative feelings $(M=-0,16, S D=$ $1,06)$. Also, an interaction of valence and PDs was observed, $F(10,202)=11,12, p<0,001, \eta^{2}=0,36$ (Figure 2 - see page 151). Further analysis of that interaction revealed that groups differ as regards both negative $(F(10,202)=8,53$, $\left.p<0,001, \eta^{2}=0,30\right)$ and positive emotional experiences $\left(F(10,202)=6,48, p<0,001, \eta^{2}=0,24\right)$. There were more negative feelings in BDL, DEP, AVD, PAR, SZD and SZT groups, (and in the OBS group on a level of tendency, $p$ $=0,083$ ) than in the NoPD group; negative feelings were more frequent in groups with BDL, DEP, AVD than in groups with OBS, ATS, NAR and HST. Additionally, all PD groups revealed less positive feelings than the NoPD group; however there were more positive feelings in the HST group than in groups with DEP and BDL.

Furthermore, analysis revealed that in several PD groups negative feelings outweighed positive ones. Negative feelings prevailed over positive ones in groups with BDL, $F(1,202)=30,45, p<0,001, \eta^{2}=0,13$, DEP $F(1,202)=29,71, p<0,001, \eta^{2}=0,13$, AVD, $F(1,202)=$ $19,73, p<0,001, \eta^{2}=0,09$, and PAR F $(1,202)=8,48, p$ $<0,001, \eta^{2}=0,04$. There was also a slight indication of prevalence of negative feelings over positive ones in the SZD group, $F(1,202)=3,35, p=0,069, \eta^{2}=0,02$. In the NoPD group this relation was reversed: positive feelings prevailed over negative ones, $F(1,202)=21,27, p<0.001$, $\eta^{2}=0,10$.

\section{"Architecture" of feelings}

To examine the differences in the components of experienced feelings between the groups, standardized scores of components of felt emotions were submitted to a $11 \times 5$ mixed model ANOVA with PDs as the betweensubjects factor and standardized scores of components of felt emotions as the within-subjects factor. There was a main effect of emotional components, $F(4,199)=2,42, p=0,05$, $\eta^{2}=0,05$. In general, behavioral expressions $(M=0,21$, $S D=1,02)$ were used more frequently than affective ones $(M=-0,15, S D=1,05)$.In addition, analysis revealed an interaction of components of emotions and PDs, $F(10,202)$ $=4,94, p<0,001, \eta^{2}=0,20$ (Figure 3). Further analysis of that interaction demonstrated that groups differ as regards to affective expressions, $F(10,202)=2,09, p=0,027, \eta^{2}=$ 0,09. Participants from the NoPD group used more affective expressions than participants in any other PDs group.

Figure 3. Scores of components of felt emotions as a function of PDs.



Note. BDL means borderline, DEP dependent, AVD avoidant, PAR paranoid, SZD schizoid, SZT schizotypal, OBS obsessive-compulsive, ATS antisocial, NAR narcissistic, HTS histronic and NoPD control group. 
There was also an effect of behavioral expressions, $F(10,202)=2,06, \quad p=0,029, \eta^{2}=0,09$. Participants in the NoPD group used more behavioral expressions than participants in the HST group and then the ATS group (on tendency level $p=0,055$ ).

Analysis revealed differences in components only in the NoPD and SZD groups. In the NoPD group affective and behavioral expressions are used more often than any other categories of expressions, $F(4,199)=7,82, p<0,001$, $\eta^{2}=0,14$. In the SZD group behavioral expressions were used more often than affective, cognitive appraisal and physiological ones, $F(4,199)=3,1, p=0,017, \eta^{2}=0,06$.

\section{Discussion}

Altogether the results indicate that participants with PDs and without PDs construct and thus experience emotions differently. In comparison to those without PDs, individuals with PDs are more receptive to emotional elicitation, show more negativity together with less positivity and what seems particularly important and noteworthy they display a deficiency in the affective component of experienced emotions. All these characteristics of emotional experiences could be considered maladaptive for several reasons.

High proneness to emotional arousal is a common feature of numerous forms of psychopathology. They occur overtly in anxiety, mood or impulse control disorders and covertly in schizophrenias (Kring, 2009; Kerns, 2005). Emotional hyperactivity is a core part of emotional over involvement associated with several maladaptive patterns of relating. One of them is hyper activation of the attachment system in attachment-anxious individuals (Mikulincer \& Shaver, 2009). Another is the EE syndrome; over involvement is one of the two aspects of EE and has been demonstrated to be specifically responsible for over controlling, self-blaming and underestimation of positive aspects of events in parents of schizophrenic and other mentally disturbed patients (Aguilera, López, Breitborde, Kopelowicz \& Zarate, 2010; Cruise, Sheeber \& Tompson, 2011).

The importance of valence of emotional reactions was repeatedly shown in the context of health and numerous other aspects of quality of life. Proficient functioning seems to require a much higher amount of positive, rather than negative feelings. According to the build-and-broad and the undoing hypotheses, experiencing positive emotions promotes personal growth and has a healing effect on both psychological and physiological injury (Cohen \& Fredrickson, 2009). The optimal proportion of positive and negative emotions is about $3: 1$. Such a ratio is rather uncommon and may be considered as an indicator of extraordinary emotional flourishing; however, substantial deviation from it - the proportion of positive and negative emotions at approximately 1:1 or lower - has been observed in individuals with depression, marital problems and jobrelated difficulties. A distorted proportion of positive and negative feelings may also be the source of general life dissatisfaction and disappointment since the prevalence of positive over negative emotions is considered a crucial factor for subjective well-being (Diener, Lucas \& Napa Scolon, 2006). In particular, deficiency in positive emotionality which was observed in all PDs - is considered maladaptive. It results in low ability to develop personal and social resources, low resilience and a poor recovery from stressrelated problems and conditions (Cohen \& Fredrickson, 2009). However, it should be pointed out that PDs differ in the degree of emotional negativity. While all are associated with low positivity of feelings, some do not exhibit high negativity of emotional experiences, and in some PDs negative feelings do not prevail over positive feelings at all. Assuming childhood maltreatment as a common factor in the development of all PDs, it is likely that the degree of resulting emotional negativity depends on the exact nature of trauma-related brain alterations. For instance, a large proportion of compensatory reward-seeking mechanisms triggered by these alterations may reduce the overall negativity effect. A higher contribution of compensatory processes may be expected to be present in the case of less intense stress or in children with higher resilience capacities. According to our data the lowest degree of negativity occurs in histrionic PD, followed by narcissistic, antisocial, obsessive-compulsive and schizotypal PDs. This raises questions about the occurrence and the character of experienced maltreatment, the biological predispositions to cope and the environmental support related to these PDs.

The general pattern of results concerning emotion reactivity and valence evidently corresponds with the data on relationships between PDs and Big Five traits (MullinsSweatt \& Widiger, 2006). All PDs are strongly associated with affective traits of Neuroticism and Extraversion, which may provide an explanation for the observed high emotion elicitation. Moreover, particular patterns of these traits associated with different PDs are in line with our results for emotional valence. In our study, individuals with BDL, DEP, AVD, PAR, SZD, SZT and, to a certain extent, OBS, which have been shown to have the most risky traitconstellation of high Neuroticism and low Extraversion, demonstrated an emotional pattern of lower positivity and higher negativity, compared to individuals without PDs. In the case of remaining PDs - that is HST, NAR and ATS - in which a positive correlation with Extraversion, an inconsistent positive correlation with Neuroticism or no correlation was observed, we noted a pattern of emotional valence similar to NoPDs.

Low contribution of affect in emotional experience makes a person vulnerable to emotional disorganization. Although all the components are considered to be inherent parts of emotion, affective phenomena have a special status as they are constitutive for emotional experience - they regulate the emotional process into a well-organized entity that captivates all information from continuous streams of facts occurring within and outside of ongoing emotion (Russell, 2009). Thus, a coherent experience of emotion, such as fear, joy or love, is the result of affectively integrated processing within multiple-component emotional systems. Therefore, deficiency in the affective component puts at 
risk the integrity, and thus the functional efficiency, of the emotional reaction.

Apart from its integrating function, awareness of affective components in the experience of emotions might contribute to rendering adaptation more efficient in yet another way. Frijda (2005) describes affective phenomena - pleasure and pain experiences - as "distinct alarm bells", by means of which the message is easily broadcasted, thus provoking numerous changes in behavior and thinking. As such they are "the vehicle by which the expectations are informed of the outcome of previous affective outcomes", which makes them crucial in motivation and learning. Thus, deficiency in affective component of emotional experiences in individuals with PDs might also explain to some extent their prominent feature - cognitive and behavioral inflexibility.

It is worth stressing that all the emotional shortcomings discussed - that is high proneness to emotional activation, lower positive emotionality and a deficiency in the affective component of experienced emotions have been observed in all ten forms of PDs. It maythus be assumed that these three features constitute a common factor for all PDs, which suggests that a similar emotional inadequacy may possibly underlie PDs psychopathology in general. This observations has at least two important implications. Firstly, similar emotional incompetence might explain to some extend shared symptomatology and high comorbidity of PDs. Secondly, and more remarkably, it reveals particular unity of all PDs on the level of faulty affective processing which confirms to some extend clinical, especially psychodynamic, notion that all PDs are rooted in disadvantageous early experiences injuring inborn capacity of all human beings for learning well-organized responding to meaningful stimulus.

If further studies confirm this assertion, it could give rise to the possibility of extending PDs therapy integrated around improving the structure and organization of emotional experiences. PDs are among the more resistant disorders to treat, partly because of persistent and fixed dysfunctional patterns that have been present throughout an individual's life and are considered to be integral to the sense of selfhood (Presnall \& Widiger, 2012). Current PDs therapies tend to deal with residuals of childhood maltreatment in the belief system and in relationship prototypes or with particular emotional problems, such as affective instability or certain fears. Notwithstanding, in order for effective change to occur a more fundamental and complete cure of emotional schemata might be needed. Moreover, commonality of some emotional factors in all PDs encourages steps towards a general treatment of these disorders.

Admittedly, several limitations of the present study should be mentioned. Firstly, PDs assessment reveals particular shortcomings as it relies exclusively on participants self-description and a single PDs measure. Also, DSM-IV-TR general diagnostic criteria for PDs have been assessed indirectly: participants have been instructed to reflect on their entire lives without scrutinizing the actual stability or lastingness of symptoms; the high frequency of symptomatic phenomena has been considered the only indices of inflexibility and pervasiveness across many situations. The comorbid Axis I disorders were also not assessed.

To sum up, our results suggest that the implementation of concepts and models from contemporary psychology of emotion might be fruitful in the expansion of understanding of PDs. Conceptualizing emotions as having multiple components allows to better comprehend the nature of emotional disturbances in PDs and may, at least partially, shed light on phenomena such as their basic similarity, comorbidity and resistance to treatment that at present remain unexplained.

\section{References}

Aguilera, A., López, S. R., Breitborde, N. J. K., Kopelowicz, A. \& Zarate, R. (2010). Expressed emotion and sociocultural moderation in the course of schizophrenia. Journal of Abnormal Psychology, 119, $875-885$.

American Psychiatric Association. (1980). Diagnostic and statistical manual of mental disorders (3rd ed.). Washington, DC: Author.

American Psychiatric Association. (2000). Diagnostic and statistical manual of mental disorders (4th ed., text rev.).Washington, DC: Author.

American Psychiatric Association. (2013). Diagnostic and statistical manual of mental disorders (5th ed.).Washington, DC: Author.

Balsis, S., Woods, C. M., Gleason, M. E. J., \& Oltmanns, T. F. (2007). Overdiagnosisand underdiagnosis of personality disorders in older adults. American Journal of Geriatric Psychiatry, 15, 742-753.

Berenbaum, H., Boden, M.T., Baker, J.P., Dizen, M., Thompson, R.T., \& Abramowitz, A. (2006). Emotional correlates of the different dimensions of schizotypal personality disorder. Journal of Abnormal Psychology, 115, 359-368.

Bland, A. R., Williams, C. A., Scharer, K., \& Manning, S. (2004). Emotion processing in borderline personality disorders. Issues in Mental Health Nursing, 25, 655-672.

Clonninger, C. R. (2007). Foreward. In W. O’Donohue, K. A. Fowler \& S. O. Lilenfeld (Eds.), Personality disorders. Toward the DSM-V (pp. vii-xv). New York: Guilford Press.

Cohen, M.A., \& Fredrickson, B.L. (2009). Positive emotions. In S.J. Lopez \& C.R. Snyder (Eds.), Oxford handbook of positive psychology (pp. 13-24). Oxford: Oxford University Press.

Cruise, C.R., Sheeber, L. B. \& Tompson, M. C. (2011). Behavioral correlates of maternal expressed emotion in interaction tasks. Journal of Family Psychology, 25, 781-784.

Dacko, M. (2011). Zaburzenia osobowości a styl przywiązania u osób w bliskich związkach partnerskich. Current Problems of Psychiatry, 12, 428-432.

Diener, E., Lucas, R. E. i Napa Scolon, C. (2006). Beyond the hedonic treademill. Revising the adaptation theory of well-being. American Psychologist, 5, 305-314.

Emmelkamp, P. M. G., \& Kamphuis, J. H. (2007). Personality Disorders. New York: Psychology Press.

Feldman Barrett, L. \& Niedenthal, P. M. (2004). Valence focus and the perception of facial affect. Emotion, 4, 266-274.

Frijda, N. H. (2005). Emotion experience. Cognition and Emotion, 4, 473497.

Frijda, N. H. (2009). Emotion experience and its varieties. Emotion Review, $1,261-271$

Gardner, K. J., Qualter, P., \& Tremblay, R. E. (2010). Emotional functioning of individuals with borderline personality traits in a nonclinical population. Psychiatry Research, 176, 208-212.

Johnson, J.G., Cohen, P., Smailes, E.M., Skodol, A.E., Brown, J. \& Oldham, J.M. (2001). Childhood verbal abuse and risk for personality disorders during adolescence and early adulthood. Comprehensive Psychiatry, 42(1), 16-23.

Kaye, A. L., \& Shea, M. T. (2000). Personality disorders, personality traits, and defense mechanisms measures. In A.J. Rush, H. A. Pincus, \& M. 
B. First (Eds.), Handbook of psychiatric measures (pp. 713-749). Washington, DC: American Psychiatric Press.

Kerns, J. G. (2005). Positive schizotypy and emotion processing. Journal of Abnormal Psychology, 114, 392-401.

Kring, A.M. (2009). Emotion disturbances as transdiagnostic processes. In M. Lewis, J.M. Haviland-Jones \& L. F. Barrett (Eds.), Handbook of emotions. Third Edition (pp. 691-705). New York: The Guilford Press.

Linehan, M. M. (1993). Skills Training Manual For Treatment of Borderline Personality Disorder. New York Guilford Press.

Linville, P.W. (1985). Self-complexity and affective extremity: don't pull all of your eggs in one cognitive basket. Social Cognition, 3, 94-120.

Lynam, D. R. \& Widiger, T. A. (2007). Using a general model of personality to identify the basic elements of psychopathy. Journal of Personality Disorders, 21,160-178.

Magnavita, J. J.,\& Carlson, T. M. (2003). Short-term restructuring psychotherapy: An integrative model for personality disorders. Journal of Psychotherapy Integration, 3/4, 264-299.

Mattia,J. L., \& Zimmerman, M. (2001). Epidemiology. In W J. Livesley (Ed.), Handbook of personality disorders (pp. 107-123). New York: Guildford Press

Mikulincer, M., \& Shaver, P. R. (2009). Adult attachment and affect regulation. In J. Cassidy \& P. R. Shaver (Eds.), Handbook of attachment. Theory, research, and clinical applications (pp. 503531).New York: Guildford Press.

Mullins-Sweatt, S. N. \& Widiger, T. A. (2006). The five-factor model of personality disorder: A translation across science and practice, In R. Krueger\& J. Tackett (Eds.), Personality and psychopathology. Building bridges (pp. 39-70). New York: Guildford Press.

Presnall, J. R. \& Widiger, T. A. (2012). Personality disorders. In J. E. Maddux \& B. A. Winstead (Eds.), Psychopathology. Foundations for a contemporary understanding (pp. 277-306). New York: Routledge.

Reips, U.-D. (2002). Standards for Internet-Based Experimenting. Experimental Psychology, 49, 243-256.

Russell, J. A. (2009). Emotion, core affect, and psychological construction. Cognition and Emotion, 23, 1259-1283.

Scherer, K. R.(2000). Emotions as episodes of subsystem synchronization driven by nonlinear appraisal processes. In M. Lewis, \& I. Granic (Eds.), Emotion, development, and self-organization (pp. 70-99). New York/Cambridge: Cambridge University Press.

Scherer, K. R.(2002). Emotion, the psychological structure of emotions. In N. J. Smelser, \& P. B. Baltes (Eds.), International encyclopedia of the social \& behavioral sciences (pp. 4472-4477). Oxford: Harvard Libraries.

Suvak, M. K., Litz, B. T., Sloan, D. M.,Zanarini, M. C., Barrett, L. F., \& Hofmann, S. G. (2011). Emotional granularity and borderline personality disorder. Journal of Abnormal Psychology, 120, 414-426.

Teicher, M., Andersen, S., Polcari, A., Anderson, C., Navalta, C., \& Kim, D. (2003). Neurobiological consequences of early stress and childhood maltreatment. Neuroscience and Biobehavioral Reviews, 27, 33-44.

Torgensen, S. (2005). Epidemiology. In J. M. Oldham, A. E. Skodol, \& D. S. Bender (Eds.). Textbookof personality disorders (pp. 129-142). Washington, Dc: American Psychiatric Publishing.

Trzebińska, E. (2002). Automatic and controlled processing in selfunderstanding. Polish Psychological Bulletin, 2, 27-36.

Trzebińska, E. \& Balsam, K. (2013). Samoocena w zaburzeniach osobowości. Przeglad Psychologiczny, 1, 15-23.

Trzebińska, E. \& Gabińska, A. (2008). Inner multiplicity and mental health: a soundness of internal voices. Studia Psychologica, 8, 215-228.

Trzebińska, E.,\& Lasota, O. (2009). Ogólna charakterystyka badań. In E. Trzebińska (Ed.) Szaleństwo bez utraty rozumu. Z badań nad zaburzeniami osobowości. (pp.102-113). Warszawa: Wydawnictwo SWPS Academica.

Widiger, T. A. (2007). Alternatives to DSM-IV: Axis II. In W. T. O'Donohue, K. A. Fowler,\& S. O. Lilenfeld (Eds.), Personality Disorders. Toward the DSM V (pp. 21-40). Los Angeles: Sage.

Widiger, T. A. \& Coker, L. A. (2002). Assessing personality disorders. In J. N. Butcher (Ed.), Clinical personality assessment: Practical approaches (pp. 407-434). New York: Oxford University Press.

Widiger, T. A. \& Samuel, D. B. (2005). Evidence-based assessment of personality disorders. Assessment, 17, 278-287.

Wilson, T. D. (2002). Strangers to ourselves: Discovering the adaptive unconscious. Cambridge, MA: Harvard University Press. 